\title{
Design and Construction of an Energy-saving Sunlight Greenhouse with Underground Drip Irrigation and Heat Storage System
}

\author{
Tiance Zhang ${ }^{1, \text { a }}$ \\ ${ }^{1}$ North China Electric Power University, Baoding, 071000, China \\ a506337351@qq.com
}

Keywords: Energy-saving sunlight greenhouse; Underground heat storage system; Warm water drip irrigation.

\begin{abstract}
A kind of energy-saving sunlight greenhouse with underground drip irrigation and heat storage system was designed and a greenhouse heat balance model was established in order to create the best artificial climate for plant growth and meets the requirement in energy conservation, environmental protection and economic operation. The project effectively combined the underground heat storage system in the greenhouse with warm water irrigation technology, and achieved the goal of collecting solar energy during the day and releasing it at night. A $500 \mathrm{~m}^{2}$ greenhouse can save the standard coal of about 5428kg in a heating season, reduce carbon dioxide emissions of $13533 \mathrm{~kg}$, save $122 \mathrm{~m}^{3}$ water per year, increase revenue of 13,100 RMB per year. From the view of energy-saving and environmental protection, this project created an effective way of heating greenhouse in winter.
\end{abstract}

\section{Introduction}

Nowadays the unheating greenhouse with the outstanding characteristic of energy saving is widely used in China ${ }^{[1]}$. But in winter, the temperature in the greenhouse is so low at night that the normal growth of plants cannot be protected. The other kind is a heating greenhouse that takes coal as energy supply. It has the defects of large energy consumption, high cost and low utilization rate. At the same time, the root has low activity because the ground temperature in the traditional greenhouse is low in winter, which will affect crop growth, reduce crop yields, and even cause chilling injury. So the research of how to make full use of solar energy to ensure greenhouse production has drawn widespread attention around the world.

Based on that, I designed a kind of energy-saving sunlight greenhouse with underground drip irrigation and heat storage system. That system achieved the goal of collecting solar energy during the day and releasing it at night. Under the condition of no artificial warming, it can meet the requirement of crops in winter and improve the utilization of greenhouse light, heat, water and other energies.

\section{Design scheme}

\subsection{Design principle}

First of all, fill the cold water tank with water. In case of good light condition, control the cold water that enters into the solar system by valve. Heat the water to $60{ }^{\circ} \mathrm{C}$ by solar energy, and inject the hot water into the incubator. In case of bad light and temperature condition, put the hot water into the radiator pipes $30 \mathrm{~cm}$ underground. Then the pipe heats the shallow ground in the greenhouse and raises the temperature to meet the requirements of the crop root. When the temperature of the radiator pipe is dropped to a certain temperature, introduce the water into the cold water tank again through water pump. At the same time, the incubator is ready for the next turn. So the project realizes the cycle control of the system ${ }^{[2]}$.

The overall design principle is shown in figures 1 and 2. 

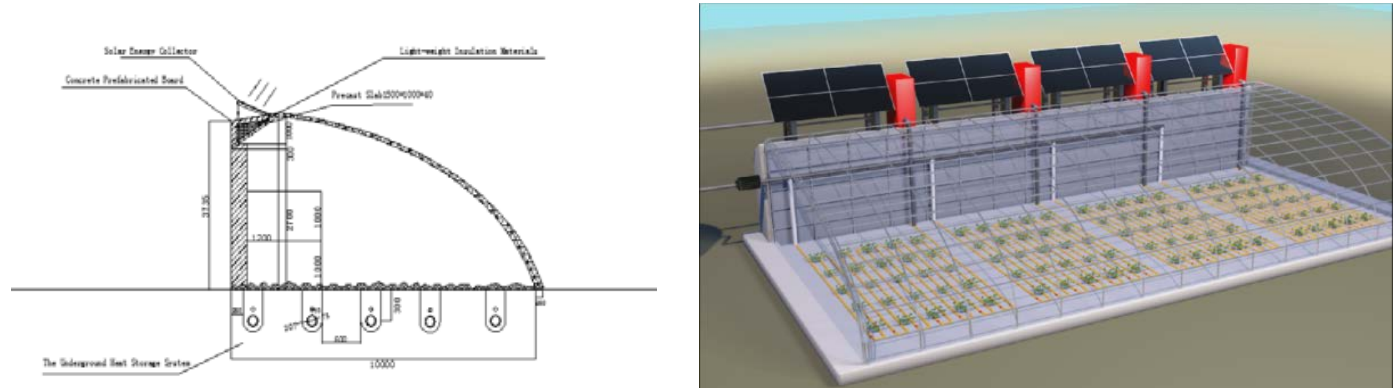

Figure 1. The greenhouse structure diagram

Figure 2. Animated diagram of greenhouse

\subsection{The system working principle and structure of each part}

\subsubsection{The solar collecting system}

As is shown in figure 4, there is an ILA-01-50 plate solar collector of $50 \mathrm{~m}$ long and $2 \mathrm{~m}$ wide. All collectors are connected to a hot water tank. The water in the collector is provided by the cold water tank.

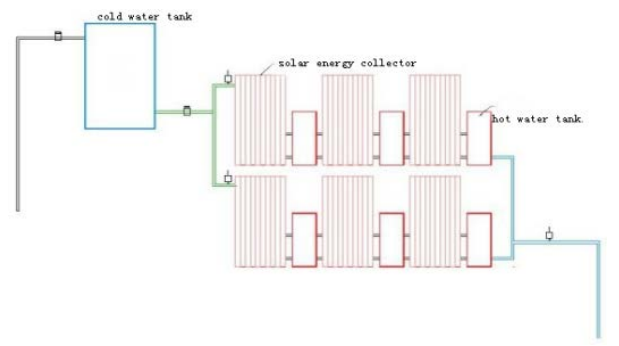

Figure 3. The structure diagram of the solar collecting system

\subsubsection{The underground heat storage system}

The underground heat storage system is divided into four parts with coiled pipe structure, as is shown in figure 5 . The discharge pipe is made of hard PVC material.

In order not to affect the growth and cultivation of crop roots, the pipelines are laid $30 \mathrm{~cm}$ underground because the plant roots are located $25 \mathrm{~cm}$ underground. Pipes with the diameter of 50 $\mathrm{mm}$ are spaced between $30 \mathrm{~cm}$. The total pipe length is $1600 \mathrm{~m}$. Hot water inflows from the east, and outflows from the west. There are bends in the north and south to increase heat dissipation. Such a piping system can effectively balance the temperature in the greenhouse [3].

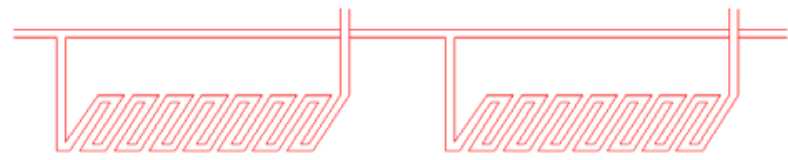

Figure 4. The part structure diagram of the underground heat storage system

\subsubsection{The drip irrigation system of warm water}

As is shown in figure 6, the drip irrigation pipe is PE pipe with $3 \mathrm{~mm}$ diameter, $25 \mathrm{~cm}$ underground and the rated flow of $2.8 \mathrm{~L} / \mathrm{h}$. The roots of plants in the greenhouse have the depth of $15 \mathrm{~cm}$ to $25 \mathrm{~cm}$ [4]. The root is surrounded by u-shape water heat preservation material. This design can effectively reduce the loss of moisture and heat.

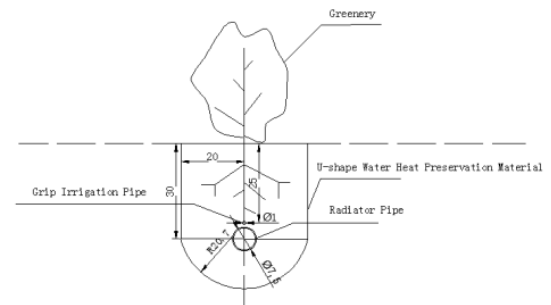

Figure 5. The design of drip irrigation system

\subsubsection{Monitoring and feedback system}

The measuring instrument of the monitoring and feedback system is shown in figure 7 and figure 8. The instrument can upload the data of real-time lighting, geotherm and others in greenhouse to the host processing system designed by myself. The system can process data and feedback the 
results to the greenhouse managers.

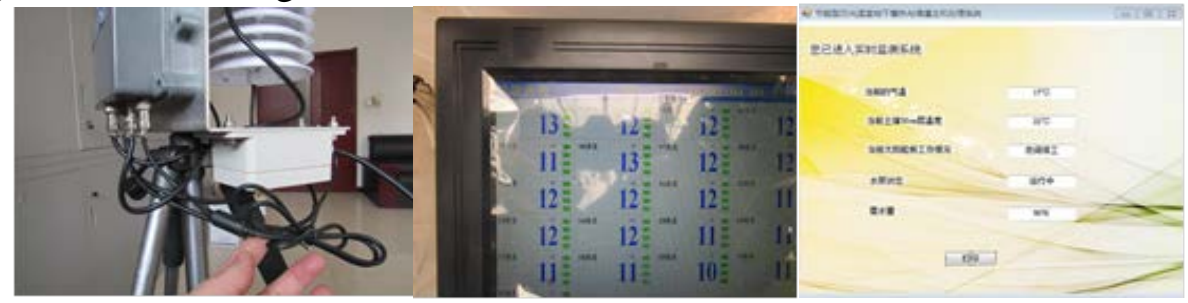

Figure 6. N-BAC20-2S detector

Figure7. Color paperless data recorder

Figure8. Host processing system

\section{Innovation and application prospects}

\subsection{Innovation}

From the view of energy-saving and environmental protection, this project creates an effective way of heating greenhouse in winter.

1) Using solar energy- clean and reduced emissions

Traditional greenhouse uses coal as energy supply which causes great energy consumption and serious pollution. This greenhouse system takes the pollution-free solar energy as the energy source, and achieves the goal of collecting solar energy during the day, releasing it at night. And the requirements of plant growth in winter can be met without raising temperature in the artificial way.

\section{2) Underground heat storage system- conducive to crop growth}

Underground radiant pipe can heat soil, make better use of solar energy, which is more conducive to plant growth. To compensate for the structural defects of the greenhouse, I designed the laying way of underground pipeline and the flow of water so that the soil temperature in the greenhouse can be uniformly heated. The loss of moisture and heat can be reduced using the $\mathrm{u}$-shape water heat preservation material.

3) Underground water irrigation system - water saving \& increased output

The underground irrigation system can decrease water evaporation, and control the temperature and humidity. The warm water consists of hot water and tap water. Warm water irrigation can restrain the diseases and insect pests and facilitate the growth of plants.

\section{4) Monitoring and feedback system- Real-time and efficient}

It can monitor and record the indicators of the greenhouse in the real-time manner, and control the whole system more accurately.

\section{5) Facing the future}

In the futural condition of grim haze in China and lack of light and heat in the greenhouse, the system can reasonably allocate solar energy resources, and achieve the sustained heating of greenhouses. New ideas are provided for greenhouse design in the future.

\subsection{Application prospect}

The energy saving system can effectively increase crop yields and has good social and economic benefits. With solar-thermal technology becoming more mature and perfect, I believe the system will have a broad application prospects and benefits.

\section{Conclusion}

In this project, I designed a kind of energy-saving sunlight greenhouse with drip irrigation and underground heat storage system and described the working principle and structure of the solar collector system, underground heat storage system, warm water drip irrigation system and monitoring and feedback system. The project effectively combined the underground heat storage system of the greenhouse with warm water irrigation technology, and achieved the goal of collecting solar energy during the day, releasing it at night. From the view of energy-saving, environmental protection, this project created an effective way of heating greenhouse in winter. 


\section{References}

[1] MA Chun-sheng. Fesearch of Solar Energy Conserving System in Soil for Active Greenhouse [D]. Shanxi Agricultural University.2003,12-17

[2] TONG Xue-jiao, SUN Zhou-ping*, LI Tian-lai, LIU Yi-ling, MA Jian. Heating Performance of Heating Device of the Solar Energy Water-Cycling System in Greenhouse [J].Journal of Shenyang Agricultural University.2016, 47(1): 92-96

[3]BAI Yi-kui. A Study on the Fire-pit and Underground Heating Exchange System of Solar Greenhouse [D]. Shenyang Agricultural University.2007,30-36

[4] Li jun. Study on Light and Temperature Environment of Northwest Energy-Saving Sun-Light Greenhouse [D].Horticulture Department of Northwest Sci-tech University of Agriculture and Forestry.2003, 3-8 